\title{
Is Extended Trochanteric Osteotomy Safe for Use in Two-stage Revision of Periprosthetic Hip Infection? A Systematic Review
}

\author{
Michael-Alexander Malahias, MD, $\mathrm{PhD}^{1}$ Roberto De Filippis, $\mathrm{MD}^{1} \quad$ Lazaros Kostretzis, MD ${ }^{1}$ \\ Alex Gu, BS ${ }^{1}$ Ivan De Martino, MD ${ }^{1}$ Peter K. Sculco, MD ${ }^{1}$

\footnotetext{
${ }^{1}$ Hospital for Special Surgery, Stavros Niarchos Foundation Complex Joint Reconstruction Center, New York, United States

Address for correspondence Roberto De Filippis, MD, The Stavros Niarchos Foundation Complex Joint Reconstruction Center, Hospital J Hip Surg 2020;4:15-22. for Special Surgery, 535 East 70th St. New York, NY 10021 (e-mail: robertodefilippis@mail.com).
}

\begin{abstract}
Keywords

- extended trochanteric osteotomy

- periprosthetic joint infection

- two-stage revision

- total hip arthroplasty

- femoral stem subsidence

- systematic review

Several clinical trials have retrospectively evaluated the role of extended trochanteric osteotomy in two-stage total hip arthroplasty (THA) revision for the management of periprosthetic joint infection of the hip. However, no systematic review of the literature has been published to date to evaluate the clinical, functional, and radiographic outcomes of extended trochanteric osteotomy (ETOs) performed as part of implant removal during a two-stage revision for the management of periprosthetic joint infection (PJI). The US National Library of Medicine (PubMed/MEDLINE), and the Cochrane Database of Systematic Reviews were queried for publications from January 1980 to April 2019 using the following keywords: "extended" AND "trochanteric" AND "osteotomy." Six studies included in this systematic review assessed 305 cases (281 patients) of PJI treated surgically with two-stage revision combined with ETO at the first stage. The mean overall union rate of the ETO was $97 \%$, while the overall rate of radiographic femoral stem subsidence $>5 \mathrm{~mm}$ was $5 \%$. In addition, the overall mean infection-free rate of two-stage revision combined with ETO was $94 \%$ (288 out of 305 operated hips), while the overall complication rate requiring reoperation was $8 \%$ (26 out of 305 operated hips). Finally, there was some evidence to show that two-stage revision with ETO was associated with improved infection-free rates compared with two-stage revision without ETO. ETO seems safe and effective in patients with wellfixed femoral stems who require two-stage THA revision for the management of chronic PJI. Two-stage revision with ETO might result in improved infection-free rates compared with two-stage revision without ETO.
\end{abstract}

Periprosthetic joint infection (PJI) associated with total hip arthroplasty (THA) is a challenging complication that occurs in 0.3 to $2.2 \%$ of cases. $^{1-4}$ Treatment of a chronically infected THA usually requires a two-stage revision surgery that involves removal of femoral and acetabular components and all associated foreign body material (wires, cables, plates), thorough debridement of the wound bed, intravenous antimicrobial therapy, and delayed re-implantation, which is both costly

received

October 10, 2019

accepted after revision

January 2, 2020

published online

February 28, 2020 and often associated with substantial morbidity. ${ }^{5,6} \mathrm{~A} \mathrm{two-stage}$ debridement procedure has a success rate of approximately $90 \%{ }^{2}$ However, the removal of well-fixed femoral stems during the first stage may result in iatrogenic damage to remaining femoral bone stock which may complicate further reconstruction. In such cases, the use of an extended trochanteric osteotomy (ETO) can be a useful tool to obtain adequate exposure that facilitates component removal, removal of retained cement,
Copyright $\odot 2020$ by Thieme Medical Publishers, Inc., 333 Seventh Avenue, New York, NY 10001, USA. Tel: +1(212) 760-0888.
DOI https://doi.org/ 10.1055/s-0040-1702987. ISSN 2472-8446. 
and allows for extensive irrigation and debridement during the first stage.

The ETO is an osteotomy that opens up the lateral onethird of the proximal femur and includes the entire greater trochanter and a portion of the femoral diaphysis and is usually 12 to $16 \mathrm{~cm}$ in length. An ETO preserves the attachments of gluteus medius, gluteus minimus, and vastus lateralis, which are levered open as a contiguous piece. ${ }^{7}$ Although ETO has been proven very useful in the setting of aseptic revision surgery, its use in patients with PJI might raise specific concerns. For example, when ETO is being used in a two-stage revision procedure, the osteotomy site may be reopened at time of second stage reimplantation. The impact of reopening an ETO on the healing response and whether an ETO in the setting PJI negatively influences trochanteric union are unknown. ${ }^{8}$ In addition, whether the metallic hardware (cables, wires, plates) typically used for the fixation of the osteotomy increases the risk of PJI recurrence is also unknown. ${ }^{9}$ Lastly, whether chronic PJI negatively impacts proximal femoral bone stock leading to increased iatrogenic damage, fracture, and overall morbidity associated with performing an ETO is also unclear. ${ }^{8}$

Recently, several publications have assessed the role of ETO in two-stage THA revision for the management of PJI. However, no systematic review of the literature has been published to date to evaluate the clinical, functional, and radiographic outcomes of ETO when used in septic patients undergoing two-stage exchange. For this reason we conducted a systematic review of the literature to assess the role of ETO when combined with two-stage revision for the management of PJI. The aims of this study were fourfold: (1) What is the union rate of ETOs performed in septic patients treated with two-stage revision? (2) What is the overall revision rate of two-stage exchange when combined with ETO for the management of patients with PJI? (3) What is the femoral stem subsidence in septic patients treated with two-stage revision combined with ETO? (4) What is the complication rate of two-stage revision when combined with ETO for the management of patients with PJI?

\section{Methods}

\section{Search Criteria}

The US National Library of Medicine (PubMed/MEDLINE), and the Cochrane Database of Systematic Reviews were queried for publications from January 1980 to April 2019 using the following keywords: "extended" AND "trochanteric" AND "osteotomy." Only abstracts that evaluated the utility of ETO in patients treated for PJI were reviewed.

\section{Inclusion and Exclusion Criteria}

The inclusion criteria were (1) studies written in English, (2) studies describing human subjects of any age and gender, (3) studies investigating the outcome of two-stage revision THA combined with ETO for the treatment of PJI, (4) studies with at least 10 patients included, (5) studies with minimum follow-up of at least 2 years, and (6) studies that provide a clinical and/or radiographic outcome measure (e.g., patient reported outcome scores, postoperative complications, functional scores, pain scale, ETO union rate, and stem subsidence rate).

The exclusion criteria were (1) non-English language articles, (2) case report studies or studies with no more than 10 patients, (3) preclinical studies, (4) studies using ETO in aseptic patients, (5) studies treating septic patients with two-stage revision without ETO, (6) studies dealing with ETO and one-stage revision in septic patients, (7) studies without outcomes (clinical/functional/radiological), (8) studies with minimum follow-up less than 2 years, (9) articles published after March 30, 2019, (10) general and systematic reviews, and (11) non-full text articles.

\section{Data Collection}

Two authors (R.D., M.M.) independently conducted the search. All authors compiled a list of articles not excluded after application of the inclusion and exclusion criteria. Discrepancies between the authors were resolved by discussion. In case of disagreement, the senior author (P.S.) was responsible for the final decision. During initial review of the data, the following information was collected for each study: title, author, year published, study design, number of patients, number of hips, gender, indication for surgery, surgical approach, type of femoral component, type of ETO fixation, length of ETO, clinical outcomes, ETO union rates, infection-free rates, stem subsidence rates, reoperation rates, and postoperative complications. Primary outcomes were (1) ETO union rate, (2) radiological signs of femoral stem subsidence, (3) survivorship of the implant/THA, (4) complication rates, and (5) infection-free rates.

The level of evidence in the included studies was determined using the Oxford Centre for Evidence-Based Medicine-Levels of Evidence. ${ }^{10}$ The methodological quality of each study and the different types of detected bias were assessed independently by each reviewer with the use of modified Coleman methodology score. ${ }^{11}$

\section{Results}

\section{Search Results}

The literature search identified 102 abstracts that were examined to determine the outcome of two-stage THA revision combined with ETO for the management of PJI (-Fig. 1). Among those, one duplicate article was identified and removed from the search. Following the removal of duplicate articles, the remaining 102 articles were subject to application of the predetermined inclusion and exclusion criteria. Following application of these criteria, nine articles were subject to a full text screening process, with three articles excluded from final analysis (- Fig. 1). Ultimately, six articles ${ }^{9,12-16}$ were found to be suitable for inclusion in the present study (-Table 1).

\section{General Characteristics}

vAll six articles were single-center studies, primarily examining the use of ETO in patients undergoing two-stage revision due to PJI. Three out of the six studies were level IV retrospective case series, ${ }^{9,13,15}$ while one study was level 


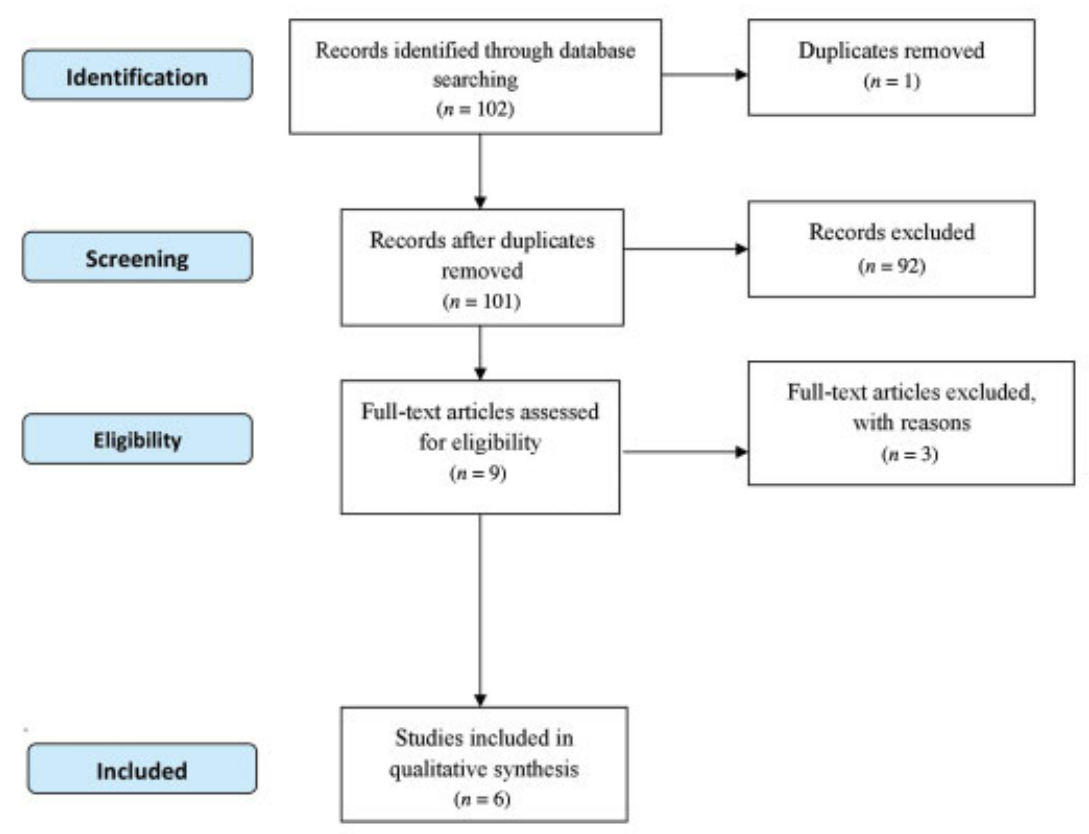

Fig. 1 Systematic review flow diagram.

Table 1 Study design, level of evidence, and modified Coleman methodology score

\begin{tabular}{|l|l|l|l|}
\hline Author(s) & Type of study & Level of evidence & Modified Coleman score \\
\hline Shi et al (2019) & Retrospective case-control study & III & 49 \\
\hline Petrie et al (2017) & Retrospective case series & IV & 49 \\
\hline Fintk and Oremek (2016) & Prospective case series & IV & 61 \\
\hline Lim et al (2011) & Retrospective case-control study & III & 48 \\
\hline Levine et al (2009) & Retrospective case series & IV & 44 \\
\hline Morshed et al (2005) & Retrospective case series & IV & 44 \\
\hline
\end{tabular}

IV prospective case series. ${ }^{16}$ The remaining two articles were level III case-control studies comparing either the outcome of two-stage revision combined with ETO in septic and aseptic patients ${ }^{14}$ or comparing the outcome of two-stage revision with and without ETO in hip PJI. ${ }^{12}$ The mean modified Coleman methodology score for methodological deficiencies of the studies was 49.2, and ranged from 44 to 61 indicating a moderate level for overall methodological quality (-Tables 1 and $\mathbf{2}$ ).

Overall, 281 patients were treated for THA PJI with a twostage exchange and 305 ETOs were performed compared with 59 patients (17\%) who did not undergo an ETO. Demographics included 183 (52\%) females and 167 males (48\%), and the mean age ranged from $52.6^{9}$ to $70.7^{16}$ years with a mean follow-up ranging from $39^{9}$ to 72.4 months $^{12}$ (-Table 2).

\section{ETO Fixation}

The indication for ETO was the same in all studies: diagnosis of chronic PJI that required removal of well-fixed cementless or cemented femoral stems. All six studies performed an ETO during the first stage of revision to remove the infected implants and insert antibiotic spacers.
All six studies reported that they used posterolateral approach for performing the ETO and two-stage revision. The ETO length was described in four studies ${ }^{12,14-16}$ with the mean length ranging from $12.5^{15}$ to $18.9 \mathrm{~cm} .{ }^{16}$ Five studies used either wires or cables for the ETO fixation (during the first step), while the number of wires/cables utilized ranged among studies between two and four. ${ }^{12-16}$ One study examined different fixation methods and number of fixators (cables, wires) and found no difference in the outcomes of ETO fixation and union. ${ }^{15}$ Finally, Morshed et al performed an ETO on the first stage, but they did not use any type of fixation in an effort to improve eradication of infection ${ }^{9}$ (-Table 3).

The type of stem explanted was reported in five studies for a total of 100 cemented stems and 83 cementless stems (-Table 3).

\section{Characteristics of Two-stage Revision}

All studies apart from one made use of different types (handmade/custom-made/use of old prostheses, articulated/nonarticulated) of impregnated antibiotic spacers (204 hips) between the first and the second stage to eradicate infection. 9,12,14-16 In contrast, one study used antibiotic beads without any spacer 
Table 2 Baseline characteristics per study

\begin{tabular}{|c|c|c|c|c|c|}
\hline Author(s) & Patients/hips & Sex & $\begin{array}{l}\text { Mean age } \\
\text { (years) }\end{array}$ & Femoral defects & $\begin{array}{l}\text { Mean follow-up } \\
\text { (months) }\end{array}$ \\
\hline $\begin{array}{l}\text { Shi et al } \\
(2019)\end{array}$ & $\begin{array}{l}48 / 48 \text { (extended } \\
\text { trochanteric } \\
\text { osteotomy } \\
\text { [ETO] group) }\end{array}$ & F 29; M 19 & $\begin{array}{l}59.2 \\
(30-78)\end{array}$ & $\mathrm{N} / \mathrm{A}$ & $72.4(25-142)$ \\
\hline $\begin{array}{l}\text { Petrie et al } \\
(2017)\end{array}$ & $99 / 102$ & F 56; M 43 & $\begin{array}{l}67 \\
(33-83)\end{array}$ & $\begin{array}{l}\text { Paprosky classification-type } 1 \text { : } \\
52 \text { cases; type } 2: 12 \text { cases; } \\
\text { unknown: } 2\end{array}$ & $66(3.6-182.4)$ \\
\hline $\begin{array}{l}\text { Fintk and } \\
\text { Oremek (2016) }\end{array}$ & $76 / 76$ & F 37; M 39 & $\begin{array}{l}70.7 \\
(43-90)\end{array}$ & $\mathrm{N} / \mathrm{A}$ & $51.2(24-118)$ \\
\hline $\begin{array}{l}\text { Lim et al } \\
(2013)\end{array}$ & $\begin{array}{l}23 / 23 \\
\text { (ETO group) }\end{array}$ & F 12; M 11 & $\begin{array}{l}58 \\
(33-79)\end{array}$ & $\mathrm{N} / \mathrm{A}$ & $58(33-79)$ \\
\hline $\begin{array}{l}\text { Levine et al } \\
\text { (2011) }\end{array}$ & $20 / 23$ & F 13; M 10 & $\begin{array}{l}61.7 \\
(30-85)\end{array}$ & $\begin{array}{l}\text { Paprosky classification-type } 2 \text { : } \\
12 \text { cases; type } 3 \text { A: } 5 \text { cases; } \\
\text { Type 3B: } 2 \text { cases; Type } 4: 4 \text { cases }\end{array}$ & $61.7(30-85)$ \\
\hline $\begin{array}{l}\text { Morshed et al } \\
\text { (2017) }\end{array}$ & 12/13 hip & F 5; M 7 & $\begin{array}{l}52.6 \\
(40-82.2)\end{array}$ & $\begin{array}{l}\text { Shaleh et al classification-grade I, } \\
3 \text { cases; grade II, } 6 \text { cases; } \\
\text { grade III, } 2 \text { cases; grade IV, } 2 \text { cases }\end{array}$ & $52.6(40-82.2)$ \\
\hline
\end{tabular}

Table 3 Surgical approach, explanted stem type, extended trochanteric osteotomy (ETO) length, type/number of ETO fixators, type of spacer, time interval between two stages

\begin{tabular}{|c|c|c|c|c|c|c|c|}
\hline Author(s) & $\begin{array}{l}\text { Surgical } \\
\text { approach }\end{array}$ & $\begin{array}{l}\text { Explanted } \\
\text { stem type }\end{array}$ & $\begin{array}{l}\text { ETO } \\
\text { length } \\
(\mathrm{cm})\end{array}$ & $\begin{array}{l}\text { ETO fixation } \\
\text { (number) }\end{array}$ & Spacer & $\begin{array}{l}\text { Interval } \\
\text { between } \\
\text { two stages } \\
\text { (weeks) }\end{array}$ & $\begin{array}{l}\text { Type of stem } \\
\text { for revision }\end{array}$ \\
\hline $\begin{array}{l}\text { Shi et al } \\
(2019)\end{array}$ & Posterolateral & $\begin{array}{l}33 \text { cemented; } \\
15 \text { cementless }\end{array}$ & $\begin{array}{l}13 \\
(10-16)\end{array}$ & $\begin{array}{l}\text { Cerclage } \\
\text { wire }(2-4)\end{array}$ & $\begin{array}{l}\text { Antibiotic impregnated } \\
\text { cement spacer in all }\end{array}$ & $\begin{array}{l}50 \\
(21-208)\end{array}$ & $\begin{array}{l}\text { Distal diaphyseal } \\
\text { cementless stems } \\
\text { in } 100 \%\end{array}$ \\
\hline $\begin{array}{l}\text { Petrie et al } \\
(2017)\end{array}$ & Posterolateral & $\mathrm{N} / \mathrm{A}$ & $\mathrm{N} / \mathrm{A}$ & $\begin{array}{l}\text { Cerclage } \\
\text { wires }(>2)\end{array}$ & $\begin{array}{l}\text { 99\% antibiotic beads; } \\
1 \% \text { cement spacer }\end{array}$ & $\begin{array}{l}23 \\
(8.7-1955)\end{array}$ & $\begin{array}{l}\text { Distal diaphyseal } \\
\text { cementless stems } \\
\text { in } 83 \% \text { and cemented } \\
\text { stem in } 17 \%\end{array}$ \\
\hline $\begin{array}{l}\text { Fintk and } \\
\text { Oremek } \\
(2016)\end{array}$ & Posterolateral & $\begin{array}{l}30 \text { cemented; } \\
46 \text { cementless }\end{array}$ & $\begin{array}{l}18.9 \\
(13-30.9)\end{array}$ & $\begin{array}{l}\text { Cerclage } \\
\text { wires (2) }\end{array}$ & $\begin{array}{l}\text { Old stem coated by } \\
\text { antibiotic spacer }\end{array}$ & $\mathrm{N} / \mathrm{A}$ & $\begin{array}{l}\text { Distal diaphyseal } \\
\text { cementless stems } \\
\text { in } 100 \%\end{array}$ \\
\hline $\begin{array}{l}\text { Lim et al } \\
(2011)\end{array}$ & Posterolateral & $\begin{array}{l}17 \text { cemented; } \\
6 \text { cementless }\end{array}$ & $\begin{array}{l}14 \\
(11-22)\end{array}$ & $\begin{array}{l}\text { Cerclage } \\
\text { wires (2) }\end{array}$ & $\begin{array}{l}\text { Antibiotic impregnated } \\
\text { cement spacer with } \\
\text { Steinman pin in } 70 \% \text {; } \\
\text { prostheses coated with } \\
\text { antibiotic cement in 30\% }\end{array}$ & $18(6-41)$ & $\begin{array}{l}\text { Distal diaphyseal } \\
\text { cementless stems 100\% }\end{array}$ \\
\hline $\begin{array}{l}\text { Levine et al } \\
(2009)\end{array}$ & Posterolateral & $\begin{array}{l}12 \text { cemented; } \\
11 \text { cementless }\end{array}$ & $\begin{array}{l}12.5 \\
(8-17)\end{array}$ & $\begin{array}{l}\text { Wires cerclage } \\
\text { (average: } 2.5 \text { ) }\end{array}$ & $\begin{array}{l}\text { Antibiotic cement spacer } \\
\text { ( } 61 \% \text { nonarticulating-39\% } \\
\text { articulating spacer) }\end{array}$ & $\begin{array}{l}14.3 \\
(7-28)\end{array}$ & $\begin{array}{l}\text { Cementless stems } \\
\text { in } 78 \% \text {; cemented in } \\
7 \% \text {; modular-tapered } \\
\text { stems in three cases }\end{array}$ \\
\hline $\begin{array}{l}\text { Morshed } \\
\text { et al (2005) }\end{array}$ & Posterolateral & $\begin{array}{l}8 \text { cemented; } \\
5 \text { cementless }\end{array}$ & $N / A$ & $\begin{array}{l}\text { No fixation at the } \\
\text { first stage. } \\
\text { Figure-of-eight } \\
\text { cable and } \\
\text { supplemental } \\
\text { diaphyseal } \\
\text { cables at the } \\
\text { second stage. }\end{array}$ & $\begin{array}{l}\text { Antibiotic impregnated } \\
\text { cement spacer in all }\end{array}$ & $\begin{array}{l}9.7 \\
(3.8-13)\end{array}$ & $\begin{array}{l}\text { Distal diaphyseal } \\
\text { cementless stems } \\
\text { in } 100 \%\end{array}$ \\
\hline
\end{tabular}

in $99 \%$ of cases (101 patients) and cement spacer in $1 \%$ (1 patient). ${ }^{13}$ The mean interval between the first and the second stage was reported in five studies ${ }^{9,12-15}$ and it ranged between $9.7^{9}$ and 50 weeks ${ }^{12}$ (- Table 3 ).

Four out of six studies reopened the ETO in all or part of their patient cohort during the second stage of the revi- sion. $9,12,14,15$ Specifically, Morshed et al reopened the ETO (which was not fixed with any type of cables/wires in the first stage) during the second stage in all cases. ${ }^{9}$ In addition, Levine et al reopened ETO during the second stage in 52\% of their treated patients for reasons related to better acetabular exposure, treatment of varus remodeling, and easier stem 
implantation. ${ }^{15}$ Shi et al and Lim et al reopened ETO in 13 and $17 \%$ of their treated patients, respectively, to deal with proximal varus deformities or to optimize stem implantation. ${ }^{12,14}$ On the contrary, Fintk and Oremek did not reopen any ETO during the second stage revision. ${ }^{16}$

The stem type chosen for revision was cementless in four out of six studies included in this review. ${ }^{9,12,14,16}$ In addition to cementless stems, Petrie et al and Levine et al utilized cemented stems in 17 and $7 \%$ of their cases, respectively ${ }^{13,15}$ (-Table 3).

Petrie et al compared cemented standard stems implanted after eradication of infection in the second stage (with suspected ETO union) versus cementless long stems with diaphyseal fixation. ${ }^{13}$ The decision on the use of standard stems was based on the assessment of the proximal femoral bone loss at the time point of the second revision stage: cases with minor to moderate bone defects were treated with standard cemented stems, while any case with severe bone loss received long stems with diaphyseal fixation. ${ }^{13}$ Regardless of the stem type, Petrie et al found no significant differences amongst groups in the postoperative outcomes at a mean follow-up of 66 months. ${ }^{13}$ Prophylactic cerclage at time of second stage was reported to be applied in one patient with osteoporotic bone. ${ }^{14}$

\section{ETO Union Rate}

The ETO union rate was evaluated by plain radiographs in all studies. The mean overall union rate of ETO after septic two stage exchange was $97 \%$ ( 295 out of 305 cases) and ranged from $87^{13}$ to $100 \%{ }^{9,14}$ Fintk and Oremek found no difference in ETO union rates between cables and wires. ${ }^{16}$ Shi reported 95\% ETO union rate at the time of second revision stage which became $100 \% 6$ months after the second stage ${ }^{12}$ (-Table 4).

\section{Radiographic Subsidence of the Femoral Stem}

Femoral stem subsidence was investigated with the use of plain radiographs in five studies. ${ }^{9,12,14-16}$ The diagnosis of stem subsidence ranged between $0^{15}$ and $15 \%{ }^{9}$ among studies. The overall rate of subsidence $>5 \mathrm{~mm}$ was $5 \%$ (9 out of 182 patients) and seven patients required revision surgery to treat this complication. Shi et al reported two cases of early subsidence $>5 \mathrm{~mm}$ (within the first 3 months) in the ETO group. ${ }^{12}$ However, they did not find any significant difference between ETO and non-ETO control groups in terms of subsidence rate ${ }^{12}$ ( - Table 4 ).

\section{Clinical/Functional Subjective Outcome Variables}

Five out of six articles included clinical/functional subjective outcome scores to assess the clinical improvement after surgery. $9,12,14-16$ The Harris Hip Score was used in four of the six studies. ${ }^{9,12,14,16}$ In addition, D'Aubigne and Postel score was used in one study. All clinical scores reported in the studies of this review were significantly improved after surgery. Further details regarding the specific mean preoperative and postoperative scores per study were listed in - Table 4.

\section{Reoperation Rate}

The reoperation rate after two-stage revision with ETO for the management of PJI was $8 \%$ (26 out of 305 operated hips). The most common reasons for reoperation were recurrence of infection (3\%; 10 patients) and dislocation (3\%; 10 patients, two of those were also found with persistent PJI). In addition, six patients (2\%) had a postoperative periprosthetic fracture requiring reoperation; five of them were treated with open reduction and internal fixation (ORIF) and one was treated with stem revision. Finally, one reoperation was due to heterotopic ossification and another one due to aseptic loosening ( - Table 4 ).

\section{Major Complication Rates}

The overall infection-free survival was $94 \%$ (288 out of 305 operated hips), and ranged from $77^{9}$ to $97 \%{ }^{13}$ Seventeen patients (6\%) were found with recurrence of PJI after ETO and two-stage revision. Interestingly, Morshed et al reported the

Table 4 Survival rate, extended trochanteric osteotomy (ETO) union rate, subsidence rate, patient-reported outcome scores, and complications

\begin{tabular}{|l|l|l|l|l|l|l|l|l|}
\hline Author(s) & $\begin{array}{l}\text { Survival } \\
\text { rate }\end{array}$ & $\begin{array}{l}\text { ETO } \\
\text { union } \\
\text { rate }\end{array}$ & $\begin{array}{l}\text { Infection } \\
\text { free rate }\end{array}$ & $\begin{array}{l}\text { Subsidance } \\
\text { rate }\end{array}$ & $\begin{array}{l}\text { Dislocation } \\
\text { rate }\end{array}$ & $\begin{array}{l}\text { Fracture } \\
\text { rate }\end{array}$ & $\begin{array}{l}\text { Clinical outcome } \\
\text { (range) }\end{array}$ & $\begin{array}{l}\text { Complications } \\
\text { (rate) }\end{array}$ \\
\hline $\begin{array}{l}\text { Shi et al } \\
(2019)\end{array}$ & N/A & $95.8 \%$ & $95.8 \%$ & $\begin{array}{l}(>5 \mathrm{~mm}) \\
2 \%\end{array}$ & $8 \%$ & $4 \%$ & Harris Hip Score 85.7 & $18.8 \%$ \\
\hline $\begin{array}{l}\text { Petrie et al } \\
(2017)\end{array}$ & $94 \%$ & $87 \%$ & $97 \%$ & $\mathrm{~N} / \mathrm{A}$ & $4 \%$ & $6 \%$ & $\mathrm{~N} / \mathrm{A}$ & $13 \%$ \\
\hline $\begin{array}{l}\text { Fintk and } \\
\text { Oremek } \\
(2016)\end{array}$ & $90.5 \%$ & $98.7 \%$ & $93 \%$ & $\begin{array}{l}(>5 \mathrm{~mm}) \\
6.6 \%\end{array}$ & $6.6 \%$ & $1.3 \%$ & Harris Hip Score: 86.6 & $14 \%$ \\
\hline $\begin{array}{l}\text { Lim et al } \\
(2011)\end{array}$ & $91.2 \%$ & $100 \%$ & $96 \%$ & $\begin{array}{l}(>5 \mathrm{~mm}) \\
4.3 \%\end{array}$ & $4.3 \%$ & $8.7 \%$ & Harris Hip Score: 81.8 & $17 \%$ \\
\hline $\begin{array}{l}\text { Levine } \\
\text { et al (2009) }\end{array}$ & $91.5 \%$ & $96 \%$ & $87 \%$ & $0 \%$ & $8.7 \%$ & $8.3 \%$ & $\begin{array}{l}\text { D'Aubigne and Postel } \\
\text { Score: } 4.8 \text { (pain); } \\
5.3 \text { (function) }\end{array}$ & $17 \%$ \\
\hline $\begin{array}{l}\text { Morshed } \\
\text { et al (2005) }\end{array}$ & $62 \%$ & $100 \%$ & $77 \%$ & $\begin{array}{l}(>5 \mathrm{~mm}) \\
15.4 \%\end{array}$ & $30.8 \%$ & $23 \%$ & Harris Hip Score: 68 & $77 \%$ \\
\hline
\end{tabular}


worst results (23\% infection recurrence rate) even though metal hardware was not used for ETO fixation during the first stage of the revision procedure. ${ }^{9}$

The mean dislocation rate was $7 \%$ (20 out of 305 operated hips), ranging from $4 \%$ (Petrie) to $31 \% .{ }^{9}$ Half of these cases (10) were treated conservatively ( - Table 4 ).

Intraoperative fractures occurred in 22 cases (7\%), while one intraoperative fracture treated with stem re-revision occurred at time of re-revision due to dislocation. ${ }^{16}$ Postoperative periprosthetic femoral fractures occurred in 15 patients (15/305 operated hips; $5 \%$ ), ranging between $1^{16}$ and $23 \%{ }^{9}$ among studies. Nine of these cases were treated conservatively. Petrie et al reported that $9 \%$ of their patients were diagnosed with postoperative trochanteric avulsion. ${ }^{13}$ All these patients were treated conservatively ${ }^{13}$ ( - Table 4 ).

\section{ETO in Septic Versus Aseptic Patients}

Lim et al compared the outcome of ETO in 23 patients who had two-stage revision for PJI with 46 aseptic patients who underwent an ETO and single stage aseptic revision. ${ }^{14}$ The mean length of osteotomy was $14 \mathrm{~cm}$ (range: $8-22 \mathrm{~cm}$ ) and the reported union rate was $100 \%$ in the PJI group and $98 \%$ in the aseptic group. ${ }^{14}$ There was not any significant difference in time-to-union among groups (10.6 weeks for infection group and 10.4 weeks noninfection group). ${ }^{14}$ In addition, no difference among groups was found in regard to the rate of stem subsidence and the overall complication rate was similar. ${ }^{14}$

\section{Two-stage Revision With and Without ETO for the Management of PJI}

Shi et al compared 48 two-stage patients with concomitant ETO to 69 two-stage revision patients without ETO. ${ }^{12}$ All patients were operated at the second stage with a cementless porous-coated, diaphyseal engaging nonmodular femoral stem (8 AML and 102 Solution revision stems; DePuy). At minimum of 2 years follow-up, the authors found significantly better results in ETO group in terms of repeated debridement rate $(2.1$ vs. $13 \%$; $p$ value $=0.037$ ) and eradication of infection rate $(95.8$ vs. $82.6 \% ; p$ value $=0.030) .{ }^{12}$ However, they found no difference in mean Harris Hip Score (85.7 vs. $86.1 ; p$ value $=$ n.s.), femoral component stability, and overall complication rate (18.8\% in ETO group vs. $20.3 \%$ in non-ETO group). ${ }^{12}$ In contrast, the mean blood loss was reduced in non-ETO group (886 vs. $1,006 \mathrm{~mL} ; p$ value $<0.001$ ), and the average duration of first operation was shorter in non-ETO group. ${ }^{12}$

\section{Discussion}

The key finding of our analysis was that the use of ETO in twostage THA revision resulted in excellent clinical outcomes for the treatment of PJI, with high midterm infection-free survival rate $(94 \%)$, and a relatively low incidence of complications requiring reoperation (8\%). All clinical/functional subjective scores which were reported in the studies included in this review were significantly improved after surgery. Moreover, the overall ETO union rate was $97 \%$, while significant ( $>5 \mathrm{~mm}$ ) femoral stem subsidence was postoperatively found in only $5 \%$ of the treated patients. Based on these findings, it is suggested that the use of ETO is safe and effective in patients with wellfixed femoral stems who require two-stage THA revision for the management of chronic PJI. In addition, the performance of an ETO during a two-stage THA revision for PJI demonstrated similar results with the use of an ETO in aseptic patients undergoing single stage revision. ${ }^{14}$ Finally, there was some evidence supporting the use of fixation devices (cables wires) to secure the ETO during the first stage. ${ }^{9}$ Interestingly, twostage revision with ETO resulted in improved infection-free rates compared with two-stage revision without ETO but larger numbers are required to confirm this finding. ${ }^{12}$ This may be related to improved direct visibility of the femoral diaphysis that may facilitate cement removal and debridement of the femoral canal.

From our initial literature search, there were no studies to deal with ETO in patients undergoing one-stage revision for PJI. In the PJI setting, ETO has been reported only in patients undergoing two-stage reimplantation procedure. As expected, all patients treated with ETO and two-stage revision were suffering from chronic PJI, so these findings may not apply on patients with acute or acute hematogenous infections.

There was no consensus regarding the ideal type and number of fixators used for the ETO. Both cables and wires were used, while the number varied between two and four cables/wires. Fintk and Oremek investigated the role of type and number of fixators (cables, wires) to find that there were not any differences in ETO union rates between different types and numbers of fixators. ${ }^{16}$ As for the use (or not) of a prophylactic cable at the stage of reimplantation, there was no adequate information provided in the studies of this review. Interestingly, none of the included studies utilized the use of a plate for the ETO fixation. Perhaps, the authors avoided the use of plates to minimize the metallic hardware usage during the first stage and, consequently, decrease the risk for PJI recurrence. Regardless, cables and wires appear sufficient for ETO union without compromising rates of infection eradication.

In contrast, Morshed et al investigated the outcome of a free-of-hardware ETO, performed without any type of fixation at the first revision stage (using an articulated antibioticimpregnated cement spacer) to minimize the risk of PJI recurrence. ${ }^{9}$ What they found was an unacceptably high rate of PJI recurrence (23\%), subsidence $>5 \mathrm{~mm}$ (15\%), dislocations (31\%), and periprosthetic fractures (23\%). ${ }^{9}$ Compared with the rest of the studies which all used ETO stable fixation in the first stage, ${ }^{12-16}$ the outcomes of the study conducted by Morshed et al were much worse. ${ }^{9}$ The results of this systematic review support the use of cables/wires to optimize ETO union as infection eradication does not appear compromised.

Furthermore, we noticed that some authors chose to reopen the ETO at the second revision stage for selected cases. ${ }^{12,14,15}$ The reasons for reopening the ETO were (1) to manage easier implantation of the long revision stem, (2) to achieve better acetabular exposure, and (3) to treat proximal varus deformities. These authors did not stratify their results between those who received an ETO reopening at the second stage and those who did not. ${ }^{12,14,15}$ Taking into consideration this dearth in the literature, we recommend that further studies are required 
to clarify the impact of ETO reopening on the clinical outcomes of these patients.

From our search, there was no study to investigate potential correlations between failure rates (subsidence rate, dislocation rate, fracture rate) or ETO union rate and the grade of proximal femoral defect. Therefore, based on the current literature, we were unable to examine if higher grades of proximal femoral bone loss due to PJI are associated with deteriorated outcomes after ETO in two-stage revision.

Petrie et al used cemented standard-length stems in patients with successful ETO union (mean time interval between surgeries: 23 weeks) who were found with supportive minor to moderate proximal femoral bone loss at the point of the second revision stage, whereas they chose cementless long revision stems in patients with unsupportive moderate to severe proximal femoral bone loss. ${ }^{13}$ When comparing these two groups, they found no significant differences in their clinical outcomes. ${ }^{13}$ Although that study ${ }^{13}$ suggested that cemented standard stems might have a role in selected cases with adequate time for ETO union between the first and the second stage and minor proximal femoral bone defects at the point of the second stage, further studies of longer follow-up are required before any final conclusions can be drawn. Based on current standard of care, the use of cementless long diaphyseal engaged femoral stems is the only safe and effective option for ETO-treated cases. ${ }^{17-20}$

Lim et al found similar results between septic patients treated with the use of ETO and reimplantation and aseptic patients undergoing ETO and reimplantation. ${ }^{14}$ In another study, Shi et al compared septic patients who underwent two-stage revision with versus without ETO. ${ }^{12}$ Interestingly, the use of ETO in septic patients undergoing two-stage revision was associated with lower rates of reinfection and repeat debridement compared with similar patients who were not treated with ETO. ${ }^{12}$ In contrast, the rate of complications and the mean functional outcomes were similar among groups. ${ }^{12}$ However, the use of ETO was associated with increased intraoperative blood loss and increased duration of the first stage surgery. ${ }^{12}$ Based on these findings, it could be suggested that although it increases the duration of the two-stage revision procedure, utilization of an ETO at time of explantation as part of a two-stage revision appears equally safe and effective in the eradication of infection compared with two-stage revision without ETO. Therefore, we recommend that in septic cases where the removal of well-fixed femoral stems during the first revision stage is difficult, the performance of an ETO should be considered as the method of choice as infection eradication as ETO union rates are excellent and comparable if not superior to non-ETO two-stage exchange.

The studies included in this analysis were not without limitations. The quality of studies, as assessed by the modified Coleman methodology score, was moderate, while no randomized controlled trial was found. The number of patients was rather small, while the follow-up varied amongst studies. In addition, there was a paucity of evidence regarding the long-term infection free survivorship and clinical outcome of patients with an ETO combined with two-stage revision. Finally, we found a dearth in the literature regarding the role of pathogens and antibiotics in the success of the operative treatment as well as the performance of different types of diaphyseal engaged femoral stems used at time of reimplantation.

\section{Conclusion}

The use of an extended trochanteric osteotomy appears safe and effective in patients with well-fixed femoral stems undergoing two-stage exchange for the management of chronic PJI. Two-stage revision with ETO has comparable, if not superior, infection-free survival rates compared with two-stage revision without ETO. The literature also supports the use of cables and wires for ETO fixation at time of implant removal as infection free survival does not appear to be negatively influenced. Finally, further studies are required to clarify the impact of ETO reopening during the second revision stage on the clinical outcomes but subsequent ETO union rates are still excellent and ETO reopening should be performed without reservation if necessary for acetabular exposure, femoral deformity, or diaphyseal stem fixation.

\section{Funding}

No funding or benefits in any form have been received or will be received from a commercial party related directly or indirectly to the subject of this article.

\section{Conflict of Interest}

Dr. Sculco reports personal fees from EOS Imaging and LimaCorporate and grants from LimaCorporate, outside the submitted work. Dr. De Martino reports that he is a paid consultant for LimaCorporate.

\section{References}

1 Tande AJ, Patel R. Prosthetic joint infection. Clin Microbiol Rev 2014;27(02):302-345

2 Lee HD, Prashant K, Shon WY. Management of periprosthetic hip joint infection. Hip Pelvis 2015;27(02):63-71

3 Lima ALL, Oliveira PR, Carvalho VC, Saconi ES, Cabrita HB, Rodrigues MB. Periprosthetic joint infections. Interdiscip Perspect Infect Dis 2013;2013:542796

4 Wetters NG, Berend KR, Lombardi AV, Morris MJ, Tucker TL, Della Valle CJ. Leukocyte esterase reagent strips for the rapid diagnosis of periprosthetic joint infection.J Arthroplasty 2012;27(8, Suppl)8-11

5 Marson BA, Deshmukh SR, Grindlay DJC, Scammell BE. Alphadefensin and the Synovasure lateral flow device for the diagnosis of prosthetic joint infection. Bone Joint J 2018;100:703-1

6 Triantafyllopoulos GK, Memtsoudis SG, Zhang W, Ma Y, Sculco TP, Poultsides LA. Periprosthetic infection recurrence after 2-stage exchange arthroplasty: failure or fate? J Arthroplasty 2017;32 (02):526-531

7 Younger TI, Bradford MS, Magnus RE, Paprosky WG. Extended proximal femoral osteotomy. A new technique for femoral revision arthroplasty. J Arthroplasty 1995;10(03):329-338

8 Mardones R, Gonzalez C, Cabanela ME, Trousdale RT, Berry DJ. Extended femoral osteotomy for revision of hip arthroplasty: results and complications. J Arthroplasty 2005;20(01):79-83

9 Morshed S, Huffman GR, Ries MD. Extended trochanteric osteotomy for 2-stage revision of infected total hip arthroplasty. J Arthroplasty 2005;20(03):294-301 
10 Oxford Centre for Evidence-based Medicine (CEBM)-Levels of Evidence (March 2009). Available at: http://www.cebm.net/oxford-centre-evidence-based-medicine-levels-evidence-march2009/. Accessed September 10, 2018

11 Sambandam SN, Gul A, Priyanka P. Analysis of methodological deficiencies of studies reporting surgical outcome following cemented total-joint arthroplasty of trapezio-metacarpal joint of the thumb. Int Orthop 2007;31(05):639-645

12 Shi X, Zhou Z, Shen B, Yang J, Kang P, Pei F. The use of extended trochanteric osteotomy in 2-stage reconstruction of the hip for infection. J Arthroplasty 2019;34(07):1470-1475

13 Petrie MJ, Harrison TP, Buckley SC, Gordon A, Kerry RM, Hamer AJ. Stay short or go long? can a standard cemented femoral prosthesis be used at second-stage total hip arthroplasty revision for infection following an extended trochanteric osteotomy?. J Arthroplasty 2017;32(07):2226-2230

14 Lim SJ, Moon YW, Park YS. Is extended trochanteric osteotomy safe for use in 2-stage revision of periprosthetic hip infection? J Arthroplasty 2011;26(07):1067-1071

15 Levine BR, Della Valle CJ, Hamming M, Sporer SM, Berger RA, Paprosky WG. Use of the extended trochanteric osteotomy in treating prosthetic hip infection. J Arthroplasty 2009;24(01): 49-55

16 Fink B, Oremek D. The transfemoral approach for removal of wellfixed femoral stems in 2-stage septic hip revision. J Arthroplasty 2016;31(05):1065-1071

17 Ladurner A, Zdravkovic V, Grob K. Femoral bone restoration patterns in revision total hip arthroplasty using distally fixed modular tapered titanium stems and an extended trochanteric osteotomy approach. J Arthroplasty 2018;33(07): 2210-2217

18 Rieger B, Ilchmann T, Bolliger L, Stoffel KK, Zwicky L, Clauss M. Mid-term results of revision total hip arthroplasty with an uncemented modular femoral component. Hip Int 2018;28(01): 84-89

19 Park YS, Moon YW, Lim SJ. Revision total hip arthroplasty using a fluted and tapered modular distal fixation stem with and without extended trochanteric osteotomy. J Arthroplasty 2007;22(07): 993-999

20 Archibeck MJ, Rosenberg AG, Berger RA, Silverton CD. Trochanteric osteotomy and fixation during total hip arthroplasty. J Am Acad Orthop Surg 2003;11(03):163-173 